\title{
Review Article \\ Effects of Solution-Based Fabrication Conditions on Morphology of Lead Halide Perovskite Thin Film Solar Cells
}

\author{
Jeremy L. Barnett, Vivien L. Cherrette, Connor J. Hutcherson, and Monica C. So \\ California State University, Chico, 400 W. 1st Street, Chico, CA 95929-0210, USA \\ Correspondence should be addressed to Monica C. So; mso@csuchico.edu
}

Received 9 April 2016; Revised 5 June 2016; Accepted 19 June 2016

Academic Editor: Rafiq Ahmad

Copyright (C) 2016 Jeremy L. Barnett et al. This is an open access article distributed under the Creative Commons Attribution License, which permits unrestricted use, distribution, and reproduction in any medium, provided the original work is properly cited.

\begin{abstract}
We present a critical review of the effects of processing conditions on the morphology of methylammonium lead iodide $\left(\mathrm{CH}_{3} \mathrm{NH}_{3} \mathrm{PbI}_{3}\right)$ perovskite solar cells. Though difficult to decouple from synthetic and film formation effects, a single morphological feature, specifically grain size, has been evidently linked to the photovoltaic performance of this class of solar cells. Herein, we discuss experimental aspects of optimizing the (a) temperature and time of annealing, (b) spin-coating parameters, and (c) solution temperature of methylammonium iodide (MAI) solution.
\end{abstract}

\section{Introduction}

Lead halide perovskite, specifically methylammonium lead iodide $\left(\mathrm{CH}_{3} \mathrm{NH}_{3} \mathrm{PbI}_{3}\right)$, is of great recent interest. Endowed with a crystal structure $\mathrm{ABX}_{3}$, in which the $\mathrm{A}$ and $\mathrm{B}$ cations are coordinated with the $\mathrm{X}$ anions, this class of perovskites has exhibited eye-catching photovoltaic performance numbers and triggered much research interest. This is largely due to its ease of processability and low cost of materials. First reported in 2012 with a $10 \%$ efficiency, the lead halide perovskite-based absorbers have more than doubled in the last four years alone. In 2016, the highest reported efficiency was $22.1 \%$, comparable with common inorganic photovoltaic materials, such as copper indium gallium selenide and cadmium telluride.

These rapid performance milestones have been reached due to the multiple fabrication methodologies developed for these devices. Despite the plethora of recent developments, there is still uncovered ground in exploring the intimate coupling of cell processing and their resultant morphology and performance metrics. The scope of this review will focus only on the most common perovskite $\left(\mathrm{CH}_{3} \mathrm{NH}_{3} \mathrm{PbI}_{3}\right)$ model. Specifically, we will survey the effects of solutionbased fabrication conditions on morphology in lead halide perovskite solar cells. Since solution processed methylammonium lead iodide perovskite thin film solar cells involving sequential deposition [1-3], solvent engineering [4], and one-step deposition have been discussed by others [5-8], we have omitted them in this review and exclusively focus on two-step deposition methods. For the most part, we have also omitted work focusing on nucleation and growth processes [9], mechanistic studies $[5,6,10]$, and stability of perovskites against moisture, air, and light, since that has been discussed elsewhere [11-17]. Importantly, this perspective does not focus on reporting devices yielding the highest efficiencies. Rather, we survey select ways of optimizing solution processing methods of perovskite solar cells. This is achieved by examining relevant literature examples, investigating the effects of (a) annealing temperature and time, (b) general spin-coating conditions, and (c) methylammonium iodide solution (MAI) temperature.

\section{Annealing Temperature and Time}

Since perovskite formation requires a certain amount of energy to drive the crystal growth $[18,19]$, thermal annealing is typically used for formation of perovskite films. Dualeh and colleagues found that changing the annealing temperature dramatically changed the film morphology, resulting in different photovoltaic performances [20].

The effect of annealing temperature on film morphology is clearly elucidated via scanning electron microscopy (SEM) in Figure 1. Samples thermally annealed at $60^{\circ} \mathrm{C}$ show large 


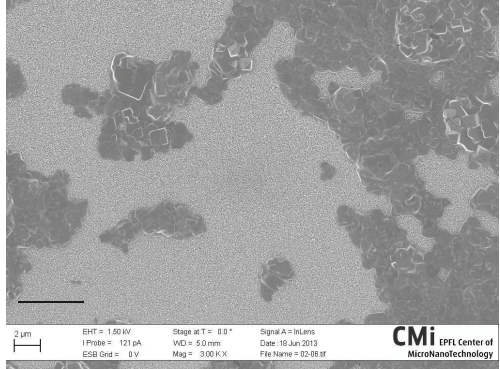

(a)

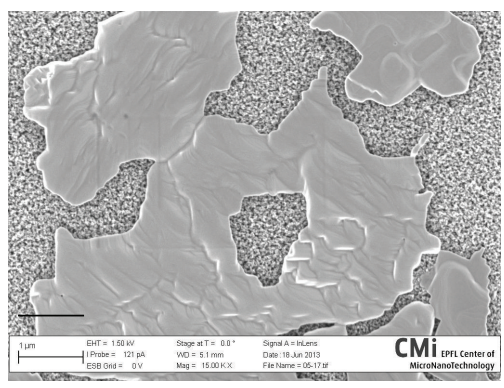

(d)

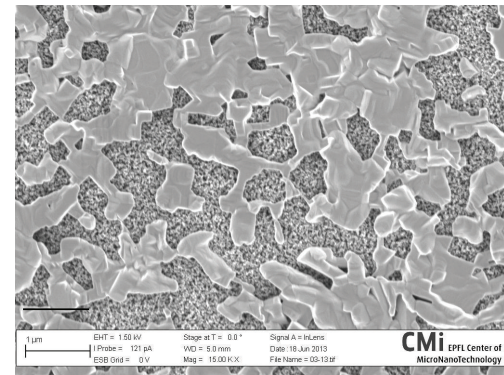

(b)

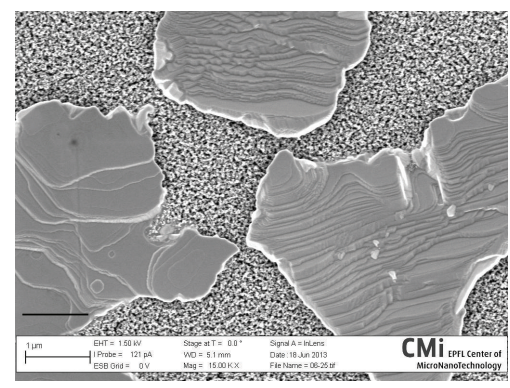

(e)

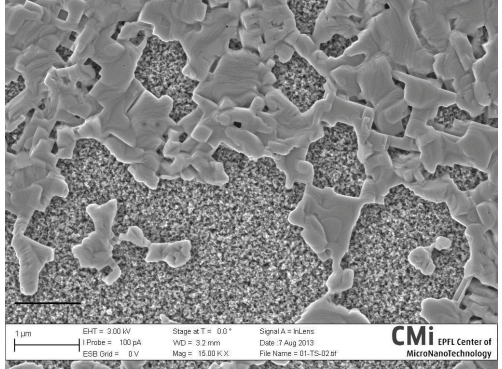

(c)

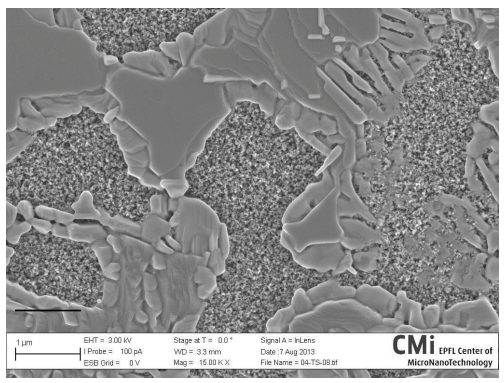

(f)

Figure 1: SEM images of perovskite annealed at (a) $60^{\circ} \mathrm{C}$, (b) $80^{\circ} \mathrm{C}$, (c) $100^{\circ} \mathrm{C}$, (d) $120^{\circ} \mathrm{C}$, (e) $150^{\circ} \mathrm{C}$, and (f) $175^{\circ} \mathrm{C}$. Reproduced from [20] with permission from Wiley-VCH.

islands of precursor materials. At $80^{\circ} \mathrm{C}$ and $100^{\circ} \mathrm{C}$, there is increased coverage of more defined crystals of perovskites. At $120^{\circ} \mathrm{C}$, the film exhibits larger sheets of perovskite. Therefore, increasing the annealing temperature leads to the merging of nuclei into sheets of material.

There is a correlation between annealing temperature and photovoltaic performance of the devices. Samples annealed at $100^{\circ} \mathrm{C}$ yielded the highest power conversion efficiency (PCE) of $11.66 \%$, followed closely by devices annealed at $80^{\circ} \mathrm{C}$ yielding PCE of 10.64\% (Table 1). These similar PCEs are attributed to the interconnected film morphology observed in Figures 1(b) and 1(c). As annealing temperature increases, the rate of crystallization increases. High temperatures result in rapid formation of large sheets from various nucleation sites. On the other hand, lower temperatures allow for slower growth and formation of smaller islands.

While others have investigated the effect of annealing temperature and time at select temperature and time points [25], Bi and colleagues have more thoroughly demonstrated that increasing the time the perovskite film is thermally annealed will allow more interdiffusion to occur resulting in a more homogeneous film [21]. In this work, both $\mathrm{PbI}_{2}$ and MAI were spin-coated, and subsequent devices were constructed with a structure of ITO/PEDOT:PSS (25 $\mathrm{nm}) / \mathrm{MAPbI}_{3}(280 \mathrm{~nm}) / \mathrm{PCBM}(20 \mathrm{~nm}) / \mathrm{C}_{60}(20 \mathrm{~nm}) / \mathrm{BCP}$ $(8 \mathrm{~nm}) /$ aluminium $(100 \mathrm{~nm})[3,21]$.

As depicted in Figure 2, absorption spans from 400 to $800 \mathrm{~nm}$, meaning the perovskite is forming within each thin film. Even the film that was only dried at $70^{\circ} \mathrm{C}$ for 15 minutes, having not been thermally annealed after, shows an absorption edge at about $800 \mathrm{~nm}$ suggesting that some perovskite is forming during the drying process. The wavelength range
TABLE 1: Relevant photovoltaic performance data for devices annealed at various temperatures. Reproduced from [20] with permission from Wiley-VCH.

\begin{tabular}{lcccc}
\hline $\begin{array}{l}\text { Temperature } \\
\left({ }^{\circ} \mathrm{C}\right)\end{array}$ & $V_{\text {oc }}(\mathrm{mV})$ & $J_{\text {sc }}\left(\mathrm{mA} \mathrm{cm}^{-2}\right)$ & FF & PCE $(\%)$ \\
\hline 60 & 779 & 3.35 & 0.68 & 1.78 \\
80 & 905 & 16.89 & 0.70 & 10.64 \\
100 & 938 & 18.37 & 0.68 & 11.66 \\
150 & 807 & 17.96 & 0.64 & 9.66 \\
175 & 755 & 15.66 & 0.70 & 8.52 \\
200 & 589 & 1.38 & 0.67 & 0.56 \\
\hline
\end{tabular}

from $600-800 \mathrm{~nm}$ shows a steady increase in absorption after 1 hour and then levels off. This steady increase in absorbance suggests that the perovskite film is not fully forming after the drying step or even after 15 minutes of annealing. In order to reach maximum absorption with a constant annealing temperature of $105^{\circ} \mathrm{C}$, perovskite films must be annealed for at least 1 hour after drying. Annealing after 1 hour will virtually have no effect on the amount of light being absorbed by the perovskite film. These results emphasize the importance that thermal annealing has on the interdiffusion of solution processed perovskite films.

$\mathrm{X}$-ray diffraction (XRD) measurements are each labeled in the overlaid spectra in Figure 3(a). After the first 15 minutes of thermal annealing, there are no visible $\mathrm{PbI}_{2}$ or MAI peaks. These peaks usually appear at $2 \theta=15^{\circ}$. There are clear XRD peaks observed at $2 \theta=16.69^{\circ}, 23.50^{\circ}, 33.40^{\circ}$, and $37.45^{\circ}$. These peaks are assigned to the specific crystal planes of the $\mathrm{MAPbI}_{3}$ 


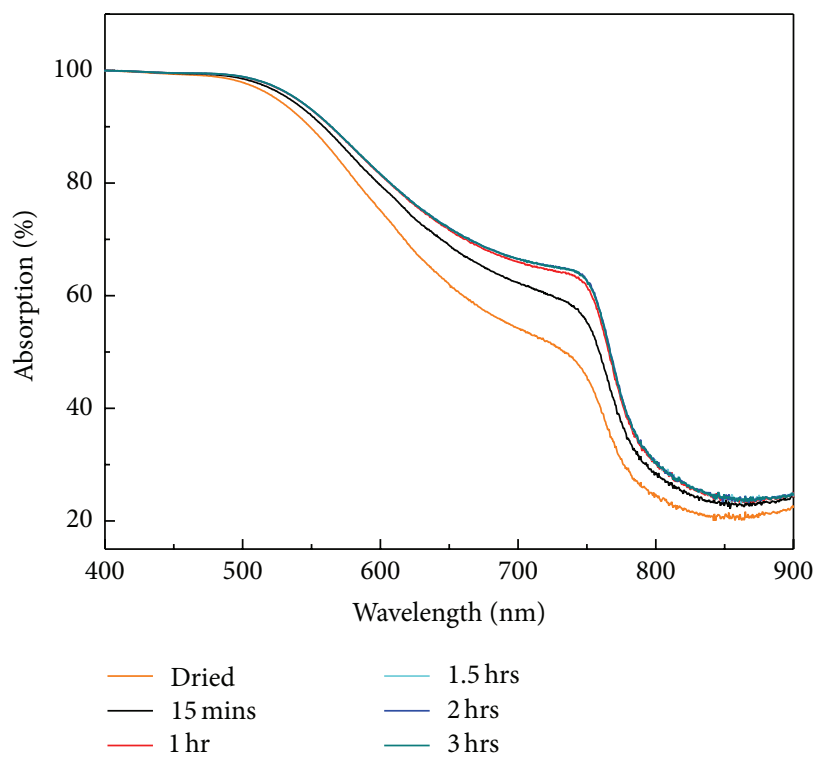

FIgURE 2: Overlaid absorption spectra of lead-based perovskite films. Films were dried at $75^{\circ} \mathrm{C}$ for $15 \mathrm{~min}$ and then annealed at $105^{\circ} \mathrm{C}$ with varying annealing times. Reproduced from [21] with permission from the Royal Society of Chemistry.

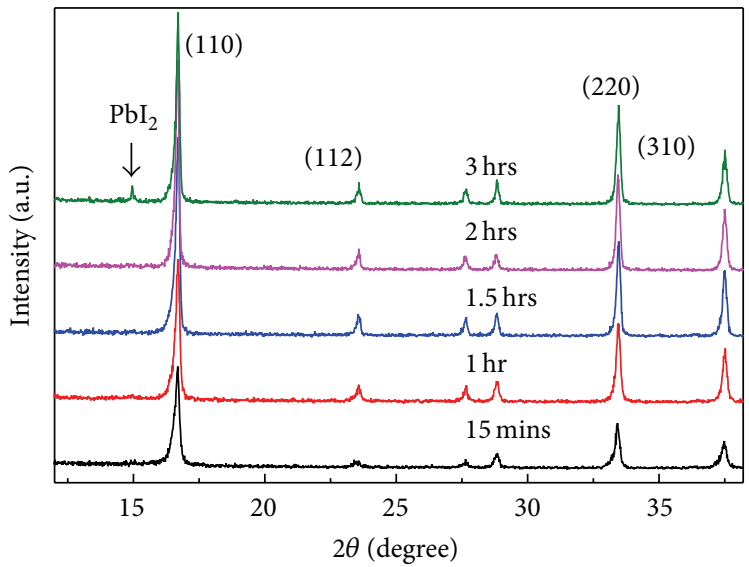

(a)

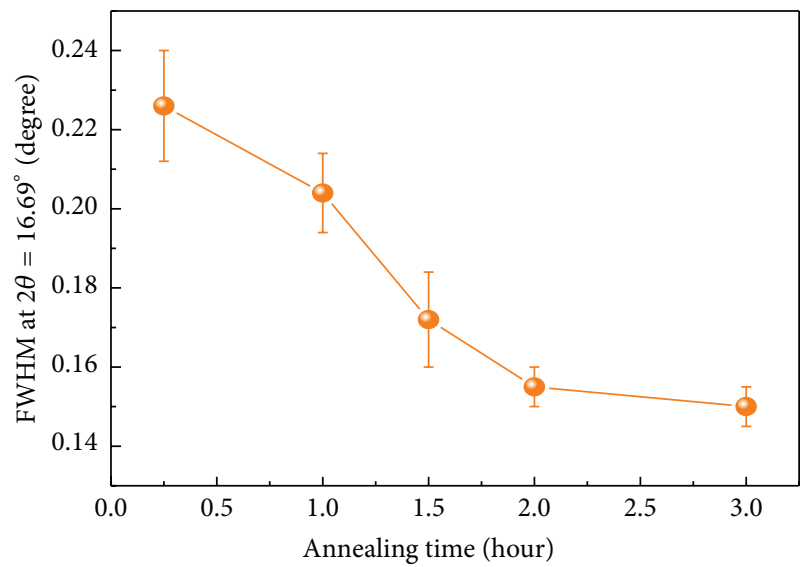

(b)

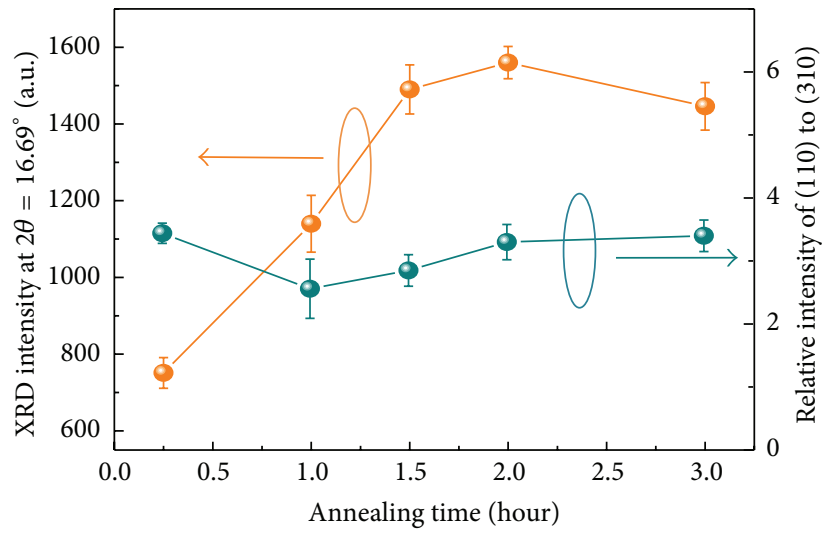

(c)

FIGURE 3: As the annealing time changes, there is an evident evolution of (a) X-ray diffraction (XRD) peaks, (b) FWHM of the (110) diffraction peak, and (c) XRD intensities. Reproduced from [21] with permission from the Royal Society of Chemistry. 
structure. The longer the annealing time is, the sharper and stronger the XRD peaks become. This is indicated by a decreasing FWHM as a function of annealing time for the (110) peak as indicated in Figure 3(b). Further, the XRD peaks increase in intensity as a function annealing time as shown in Figure 3(c). This is consistent with the SEMs in Figures 4(a)$4(\mathrm{~g})$.

Noticeably, after 3 hours of annealing, a small amount of $\mathrm{PbI}_{2}$ appears in Figure 3(a). This suggests decomposition of the perovskite films. For trihalide perovskites, long-term annealing after 3 hours tends to decompose the perovskite film. On the other hand, short-term annealing of 15 minutes of trihalide perovskites does not improve the crystallinity of the perovskite film in Figure 4(a). A recent study by Ma and colleagues concluded that the crystallinity is influenced by the volatility of DMF used in the formation of $\mathrm{PbI}_{2}$ solution [22]. Further, they suggest that using a mixed halide solution will add excess chloride ions that help improve crystallinity and morphology.

Figures 4(a) and 4(b) display the film morphology with only $5 \mu \mathrm{m}$ of magnification in the films after thermal annealing, for 15 minutes and 3 hours, respectively. The bright spots from Figure 4(a), the film with 15 minutes of annealing, are lighter in color than those in Figure 4(b), the film with 3 hours of annealing. The bright spots from Figure 4(a) film display more charge buildup than those in Figure 4(b), possibly due to the lack of interdiffusion of perovskite from the shorter annealing time. Figures $4(\mathrm{c})-4(\mathrm{~g})$ show the changes in morphology with increasing thermal annealing time. Figure $4(\mathrm{~h})$ shows grain size distribution curves generated from the images.

Although a one-step deposition method was used for the XRD and SEM data in Figures 5(a) and 5(b), changing annealing time using the one-step method yields similar peaks and trends that agree with the two-step deposition method. In Figure 5(a), the SEM image indicates that trihalide perovskite films annealed for $15 \mathrm{mins}$ at $100^{\circ} \mathrm{C}$ have grain sizes that are approximately $100 \mathrm{~nm}$ thick. There is also some $\mathrm{PbI}_{2}$ that shows up in the XRD. This could possibly be unreacted $\mathrm{PbI}_{2}$ or the fact that the decomposition process is starting to occur. Figure 5(b) illustrates a mixed halide system incorporating both $\mathrm{MAPbI}_{3}$ and $\mathrm{MAPbCl}_{3}$. Long-term annealing dramatically decreases the $\mathrm{MAPbCl}_{3}$ peak. Excess chlorine ions may form the chloride-containing amorphous phase that melts at around $100^{\circ} \mathrm{C}$ in mixed halide perovskite layers. During prolonged annealing, the "melted amorphous phase with highly moveable ions may supply ions needed for the growth of $\mathrm{MAPbI}_{3}$ crystals" [22]. The evaporation of excess ions, methylammonium and chloride, promotes the transformation of $\mathrm{MAPbCl}_{3}$ from $\mathrm{MAPbI}_{3}$. Crystallinity does indeed improve as seen in the SEM image in Figure 5(b). There are fewer pinholes. The film is more smooth and homogenous with grain sizes that are about $500 \mathrm{~nm}$ thick. The chloride ions are reported to act as dopants and surface passivant which facilitates charge transfer at grain boundaries and electrical interfaces [35]. Mixed halide perovskite films have shown great promise with PCEs now surpassing 19\% [36]. It is evident that increasing the annealing time in a mixed halide system will increase the
TABLE 2: Shunt and series resistances of devices with perovskite films annealed at $105^{\circ} \mathrm{C}$ with varying annealing times. Reproduced from [21] with permission from the Royal Society of Chemistry.

\begin{tabular}{lccccc}
\hline Annealing time $(\mathrm{h})$ & 0.25 & 1 & 1.5 & 2 & 3 \\
\hline Series resistances $\left(\mathrm{ohm} \mathrm{cm}^{2}\right)$ & 5.46 & 3.49 & 1.67 & 1.78 & 1.43 \\
Shunt resistances $\left(\times 10^{4} \mathrm{ohm}\right)$ & 1.51 & 1.68 & 2.57 & 3.83 & 3.71 \\
\hline
\end{tabular}

grain sizes and film homogeneity which may lead to higher efficiencies.

There is a gradual increase in grain size as the thermal annealing time increases. This is consistent with the decreasing FWHM in the XRD data. After 15 minutes of thermal annealing, the average perovskite grain size is $190 \mathrm{~nm}$. Films that were thermally annealed for 2 and 3 hours displayed the largest averages in grain size of about $350 \mathrm{~nm}$ and $380 \mathrm{~nm}$. The maximum grain size was observed between 600 and $700 \mathrm{~nm}$ at films thermally annealed after 1.5 hours. Figure 6 suggests that the grain size increases the most (ca. 35\%) between 60 and 90 minutes with grain sizes ranging between 230 and $310 \mathrm{~nm}$. However, after $1.5 \mathrm{hrs}$ of annealing, the grain sizes seem to level off. This suggests that grain sizes increase the most within the first $1.5 \mathrm{hrs}$ of thermal annealing. The grain size is larger than or equal to the thickness of the film. It is clear that, with increasing thermal annealing time, the grain sizes will increase as well, allowing more interdiffusion [32]. This contributes to minimized grain boundary in the charge collection direction of the annealed perovskite films which may influence cells to have higher efficiencies [32].

From the previous results, the length of time during which the perovskite film is thermally annealed has a critical role in the formation and morphology of the crystalline film. Generally, an increase in grain size of the perovskite crystals forms a more compact film, resulting in a decrease in the grain boundaries. These boundaries act as trap sites for charges, ultimately reducing the photovoltaic performance of the perovskite thin film. After 2 hours of thermal annealing, $J_{\text {sc }}$ increased from $14.9 \mathrm{~mA} \mathrm{~cm}^{-2}$ to $19 \mathrm{~mA} \mathrm{~cm}^{-2}$, while $\mathrm{FF}$ increased from $69 \%$ to $78 \%$ as shown in Figure $7(\mathrm{a})$. The FF did not decrease with further annealing as shown in Figure $7(\mathrm{~b})$. The nearly $27 \%$ increase in $J_{\mathrm{sc}}$ and $13 \%$ increase in FF lead to optimized device performance. A PCE of $13.4 \%$ was obtained when cells were annealed at $105^{\circ} \mathrm{C}$ for 2 hours after drying. When the cells are thermally annealed for a longer time after drying, the series resistance decreases but exhibits more shunt resistance than those thermally annealed for shorter amount of time. In Table 2, the shunt resistance increased from $1.51 \times 10^{4} \Omega$ to $3.71 \times 10^{4} \Omega$ as a function of annealing time. Generally, series resistance tends to decrease, as the annealing time of perovskite film increases. In contrast, the shunt resistance increases with increasing annealing time of the perovskite film. Interestingly, a sample that was annealed for 2 hours showed the most shunt resistance at 3.83 $\times 10^{4} \Omega$. Again, it is possible to improve the film morphology and increase the grain sizes by doping the perovskite film using mixed halides. This could improve efficiencies to $19 \%$ or higher [36]. 


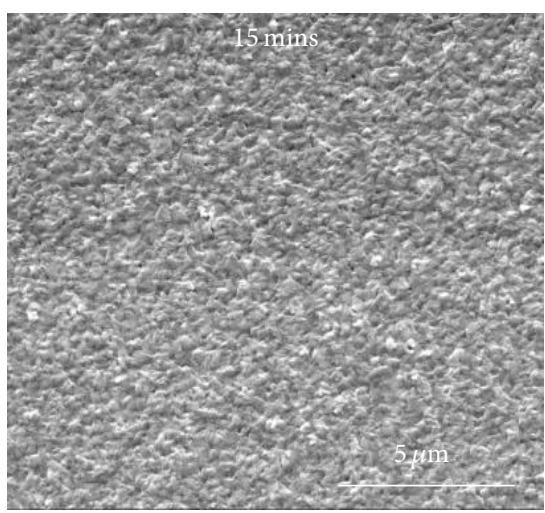

(a)

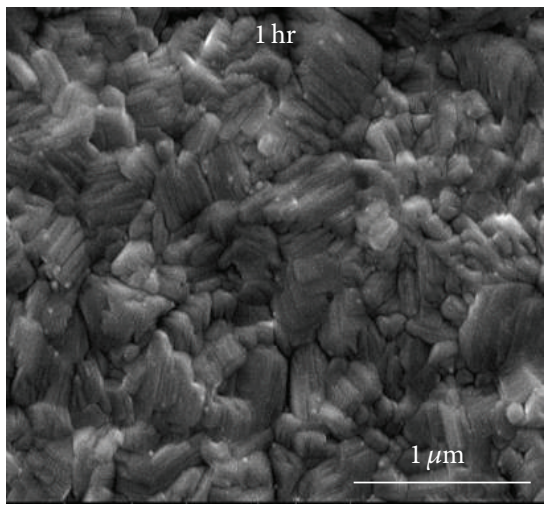

(d)

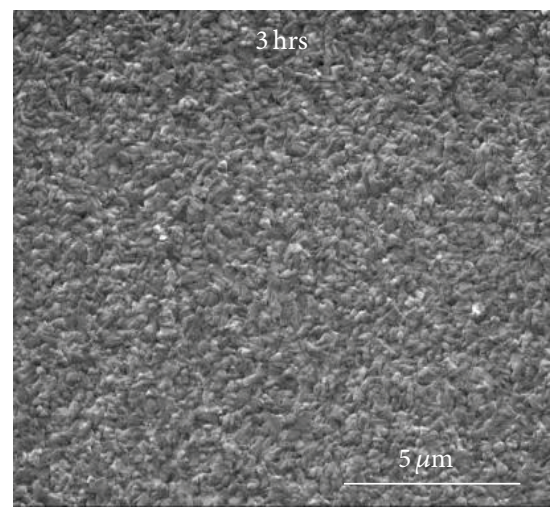

(b)

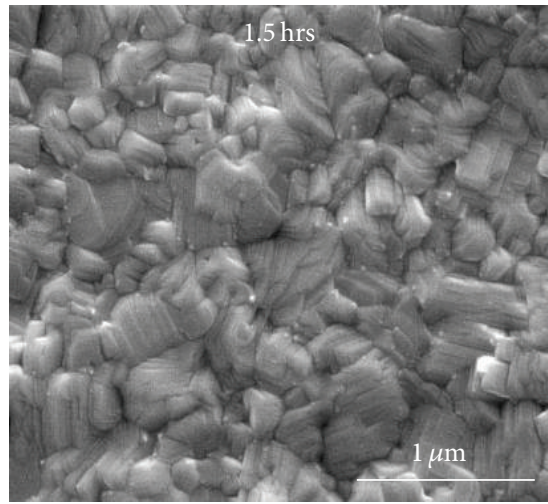

(e)

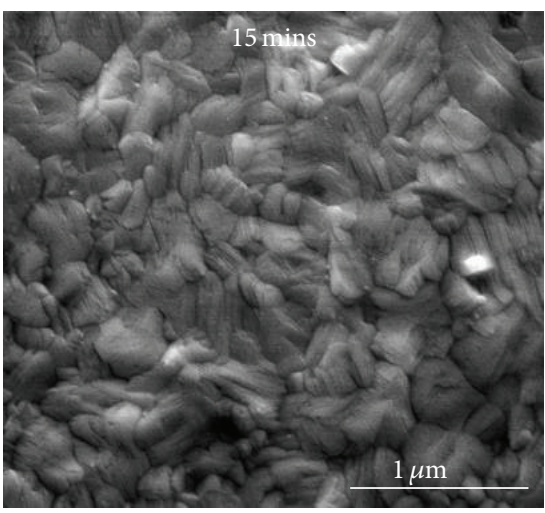

(c)

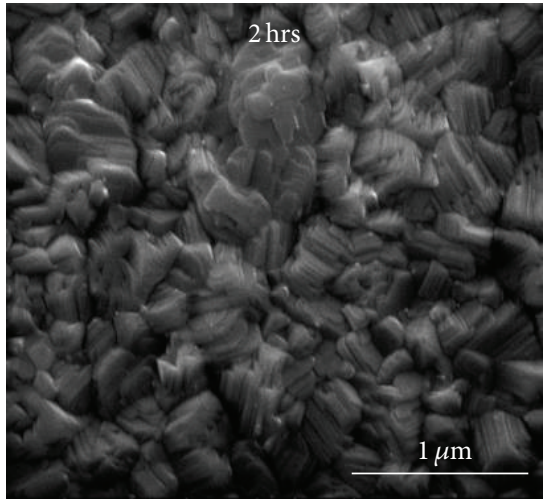

(f)
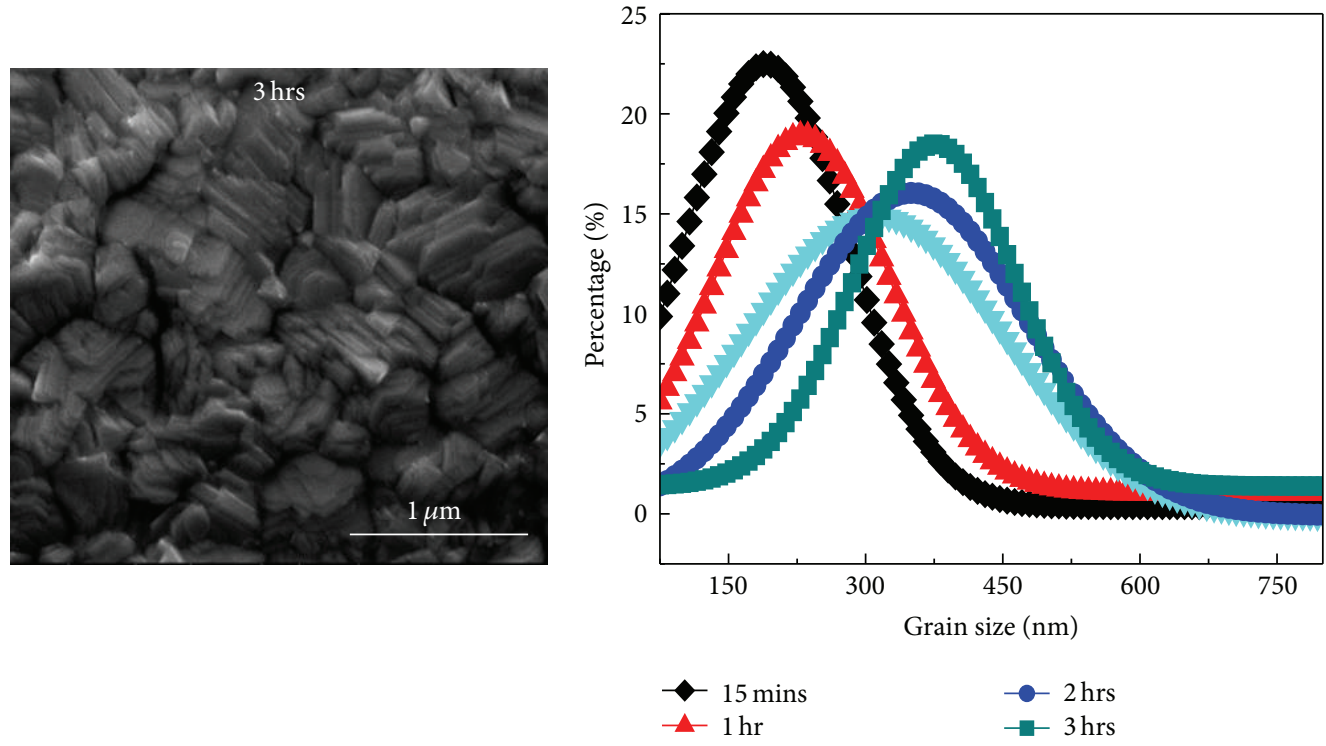

(g)

(h)

FIGURE 4: Grain sizes of perovskite crystal increase as a function of annealing time as shown in (a-g) top-down SEM images and (h) grain size distribution plot of films. Reproduced from [21] with permission from the Royal Society of Chemistry.

\section{Spin-Coating Conditions}

The morphology of perovskite layers is intimately correlated to the efficiency of the resulting lead halide perovskite solar cell device. To facilitate the formation of these layers, one must select specific processing techniques. Among the most popular deposition techniques for the application of the $\mathrm{PbI}_{2}$ layer and electron transporting layers is spin-coating. This technique involves the even application of thin layers of solution-based materials with adjustable spin time and rate. 


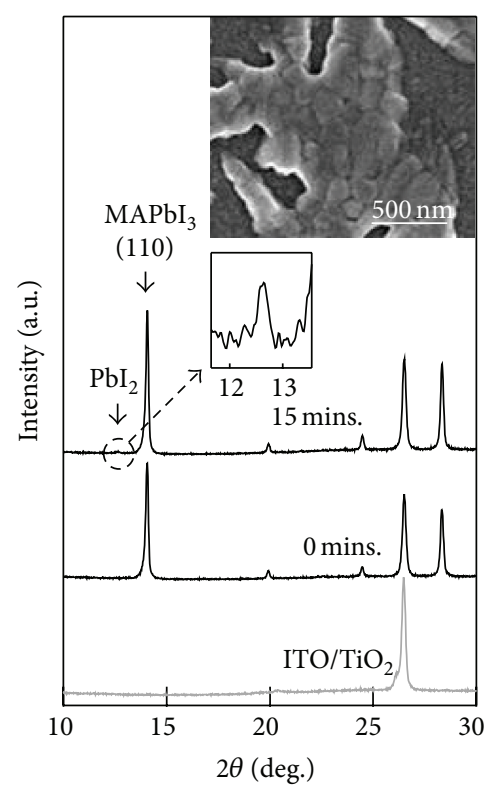

(a)

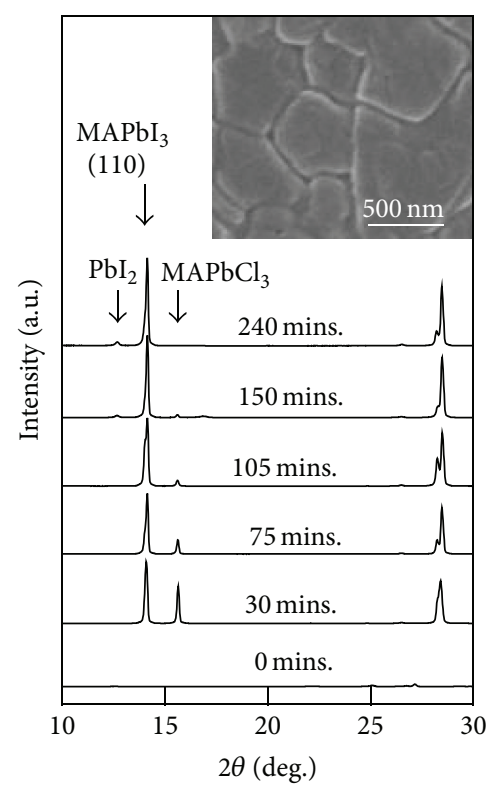

(b)

FIGURE 5: (a) XRD data for tri-iodide perovskite annealed at $100^{\circ} \mathrm{C}$ with varying annealing times. Inset shows SEM of perovskite film annealed for 15 mins at $100^{\circ} \mathrm{C}$. (b) XRD data for mixed halide perovskite annealed at $100^{\circ} \mathrm{C}$ with varying annealing times. SEM of perovskite film annealed for 150 mins at $100^{\circ} \mathrm{C}$. Reproduced from [22] with permission from the Royal Society of Chemistry.

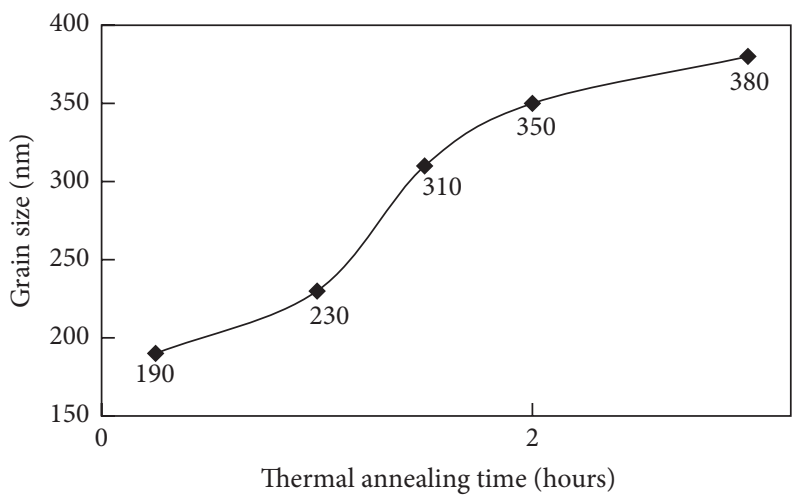

FIGURE 6: Plot of highest percentage of grain size present in each film with increasing thermal annealing time.

These parameters ultimately control the film thickness and uniformity. Unlike vapor deposition which requires a vacuum chamber for film deposition [23,31,37], spin-coating does not; it affords reproducible film uniformity while being more economically feasible.

Liu et al. compared the results of the spin-coating procedure of the $\mathrm{PbI}_{2}$ layer with that from vapor deposition [23]. After examining the films by SEM, conductivity, profilometry, UV-vis, XRD (unreacted $\mathrm{PbI}_{2}$ ), and power conversion efficiency, they showed that the samples made by spin-coating were nearly equivalent to those made by vapor deposition technique. In other words, even though vapor deposition differs from spin-coating by the former technique using a solvent-free deposition technique, this variation in technique resulted in similar properties in the films. For example, the XRD patterns of evaporated (E) and spin-coated (S) samples are nearly identical in Figure 8(a). Further, the top-down
SEM images show roughly similar crystal grain sizes in Figures 8(b) and 8(c).

This suggests that either the two methods apply similar layers or the MAI application step plays a larger role in crystal growth. The $J-V$ curves and incident photon-to-current efficiency (IPCE) spectra were also compared, showing nearly identical results in Figure 9.

Lastly, to compare crystallization and unreacted $\mathrm{PbI}_{2}$ in each application method, powder XRD was performed. Both processes failed to eliminate unreacted $\mathrm{PbI}_{2}$ and display only minor differences in crystal structure in Figure 10. This could be due to the short MAI dipping times, which were on the timescale of a few minutes. Previously, Liang and colleagues noted that 1 to 3 hours is required for complete conversion of the film to black and uniform $\mathrm{CH}_{3} \mathrm{NH}_{3} \mathrm{PbI}_{3}$ [38]. Notably, both methods form weakly crystalline $\mathrm{PbI}_{2}$ layer, as observed in the broad and weak peaks in the XRD. Wu et al. 


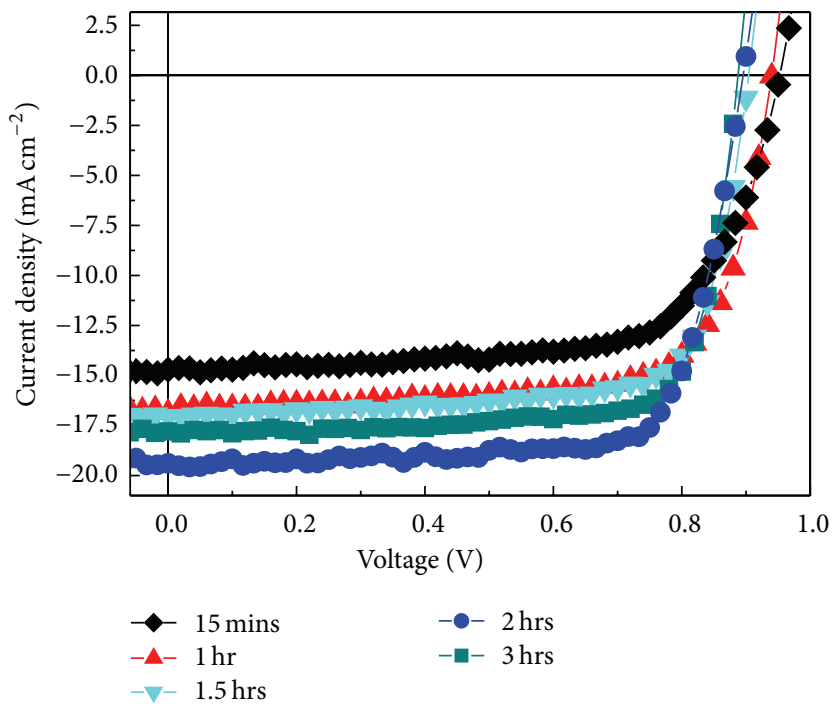

(a)

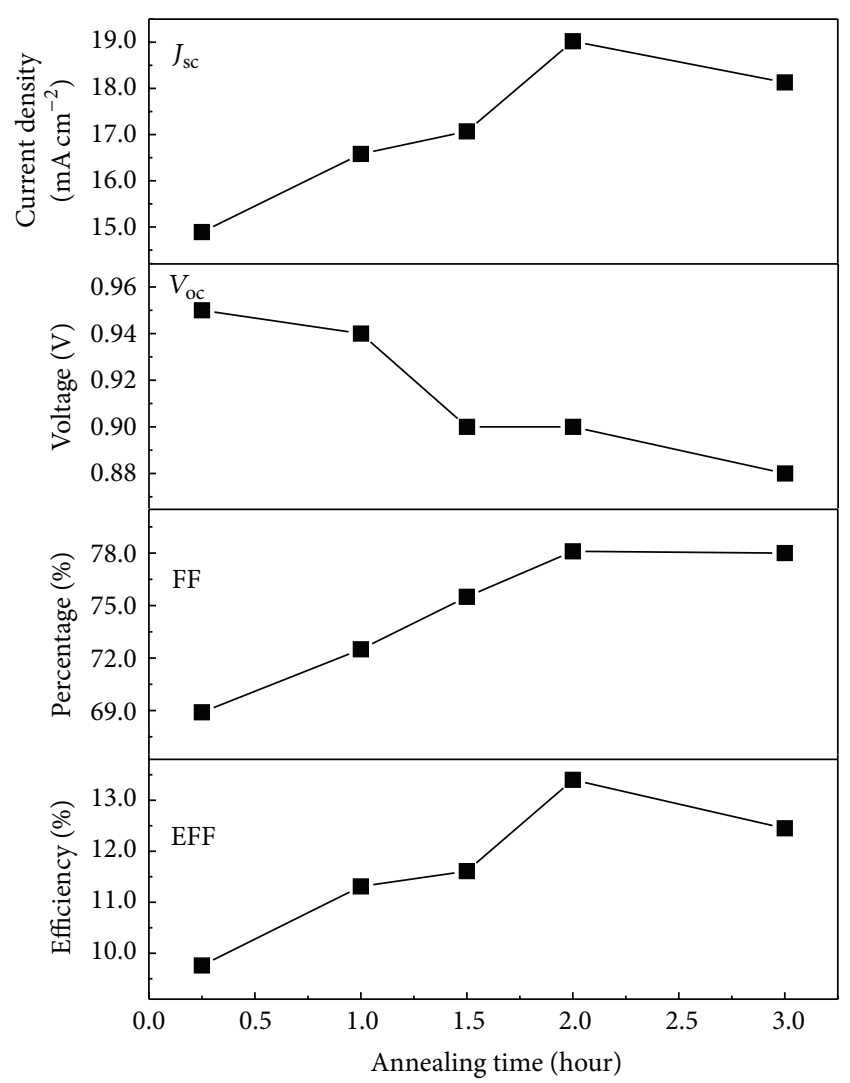

(b)

FIGURE 7: Electrical performance of devices with $\mathrm{MAPbI}_{3}$ perovskite films annealed at $105^{\circ} \mathrm{C}$ for varying annealing times: (a) $J-V$ curves of the devices under simulated AM 15 irradiation $\left(100 \mathrm{~mW} \mathrm{~cm}^{-2}\right)$; (b) variation of device parameters, $J_{\mathrm{sc}}, V_{\mathrm{oc}}, \mathrm{FF}$, and PCE, with increased annealing times. Reproduced from [21] with permission from the Royal Society of Chemistry.

also previously showed that noncrystalline, amorphous $\mathrm{PbI}_{2}$ layers increased MAI interactions and improved perovskite formation [3].

Currently, there is no comprehensive work on optimizing the spin-coating procedure, since optimization appears to be performed by individual labs. Though the time of spincoating is often not specified, the speed and concentrations are noted. Authors report 1600-7000 rpm and 5-60 seconds of spin-coating $[1,23,26-30,33,34,38-41]$ with ca. $1 \mathrm{M}$ concentrations of $\mathrm{PbI}_{2}$. These procedures result in PCEs of up to ca. $15 \%$.

Table 3 compares various perovskite thin films, for which the lead iodide layer is applied with a spin coater. Efficiencies achieved are not directly attributed to the method of $\mathrm{PbI}_{2}$ application. Notably, quality perovskite photovoltaic cells can be produced using this facile application method. The spin-coating speeds and time of a coating do not tell the whole story, since many procedures are vastly different. For example, Shi and coworkers follow the application of $\mathrm{PbI}_{2}$ with a dipping method of MAI to form the perovskite crystal [29]. Eze et al. follow the $\mathrm{PbI}_{2}$ with a spin-coating of a MAI solution [28]. Interestingly, Yella et al. followed the
TABLE 3: Solution processed perovskite $\left(\mathrm{CH}_{3} \mathrm{NH}_{3} \mathrm{PbI}_{3}\right)$ solar cells fabricated under various conditions.

\begin{tabular}{lcccc}
\hline $\begin{array}{l}{\left[\mathrm{PbI}_{2}\right]} \\
(\mathrm{M})\end{array}$ & $\begin{array}{c}\text { Spin-coating } \\
\text { speeds }(\mathrm{rpm})\end{array}$ & $\begin{array}{c}\text { Spin-coating } \\
\text { time }(\mathrm{s})\end{array}$ & PCE (\%) & Refs. \\
\hline 1.2 & 2000 & 60 & 10.47 & {$[26]$} \\
1.1 & 2000 and 6000 & 5 and 10 & 13.28 & {$[27]$} \\
1.0 & 3000 & 15 & 12.73 & {$[28]$} \\
1.0 & $\mathrm{n} / \mathrm{a}$ & $\mathrm{n} / \mathrm{a}$ & 13.9 & {$[29]$} \\
1.0 & 6000 & 10 & 11.16 & {$[30]$} \\
1.0 & 7000 & $\mathrm{n} / \mathrm{a}$ & 12.4 & {$[31]$} \\
1.0 & 3000 & 15 & 11.8 & {$[32]$} \\
1.0 & 2500 & $\mathrm{n} / \mathrm{a}$ & 10.2 & {$[33]$} \\
1.0 & 4000 & 30 & 13.7 & {$[34]$} \\
1.0 & 6500 & 5 & 12 & {$[1]$} \\
\hline
\end{tabular}

$\mathrm{PbI}_{2}$ application by a 1-2-second dip of 2-propanol [40]. These protocols suggest that different procedures are often tailored for specific uses and layer thickness. Understanding the complexity and modularity of perovskite solar cells makes 


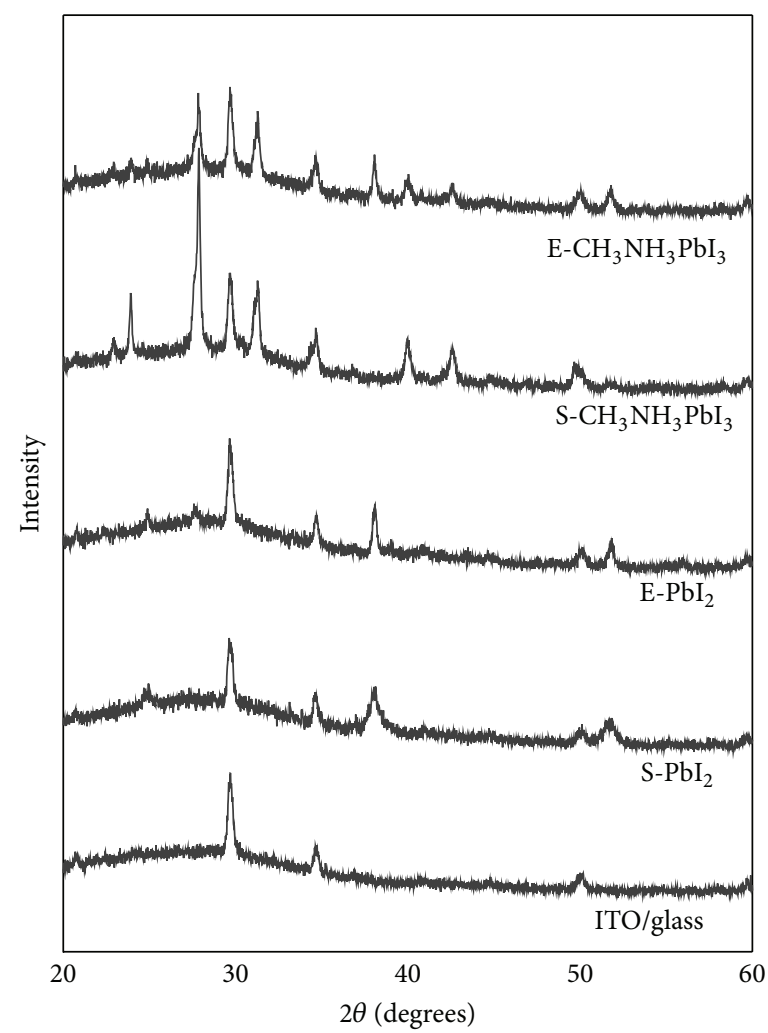

(a)

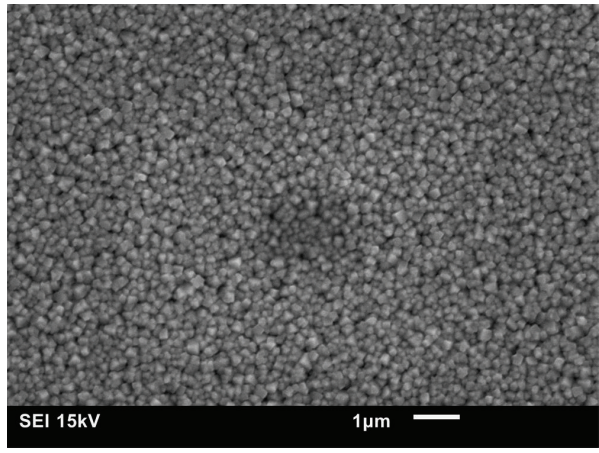

(b)

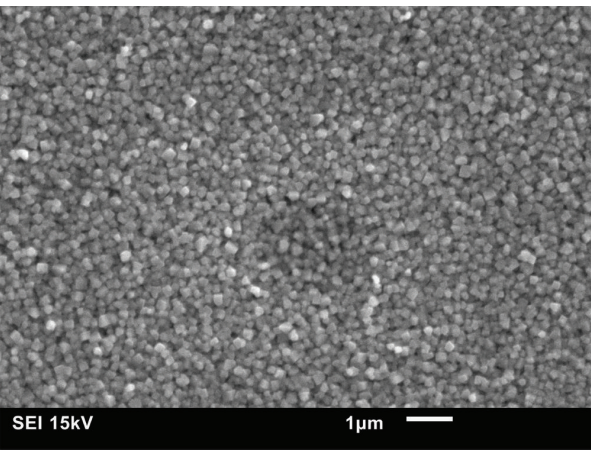

(c)

FIGURE 8: (a) XRD of evaporated and spin-coated layers. SEM of (b) spin-coated and (c) vapor deposited perovskite crystals. The XRD and SEM data suggest nearly identical crystal growth from spin-coating and vapor deposition of the $\mathrm{PbI}_{2}$ layer. Reproduced from [23] with permission from the Royal Society of Chemistry.

it difficult to specify which procedure is superior. However, it is beneficial to compare techniques and results from various groups, since spin-coating is one of the most adaptable thin film fabrication processes.

\section{Methylammonium Iodide (MAI) Solution Temperature}

A critical factor affecting the grain size of the perovskite crystals is the temperature at which the MAI is deposited onto the $\mathrm{PbI}_{2}$ layer. Ahn and colleagues performed an experiment where the solution temperature of 0.050 MAI was varied [24]. Both the substrate and the MAI solution are preheated at different temperatures of $-10^{\circ} \mathrm{C}, 20^{\circ} \mathrm{C}$, and $50^{\circ} \mathrm{C}$, while MAI concentration is fixed at $0.050 \mathrm{M}$. SEM imaging elucidated how the grain size is, in fact, dependent on the solution temperature of MAI (Figure 11). A theoretical model was also proposed to rationalize the temperature dependence of perovskite crystal formation.

As temperature of the MAI solution increases, the equilibrium concentration of the chemical reaction increases due to increased solubility of the MAI. At high temperatures, the critical free energy is higher than at low temperatures which determines the number of nuclei. This results in a decrease of the number of nuclei growing into $\mathrm{MAPbI}_{3}$ crystals leading to an increase of $\mathrm{MAPbI}_{3}$ grain size. In Figure 11, the $\mathrm{MAPbI}_{3}$ 


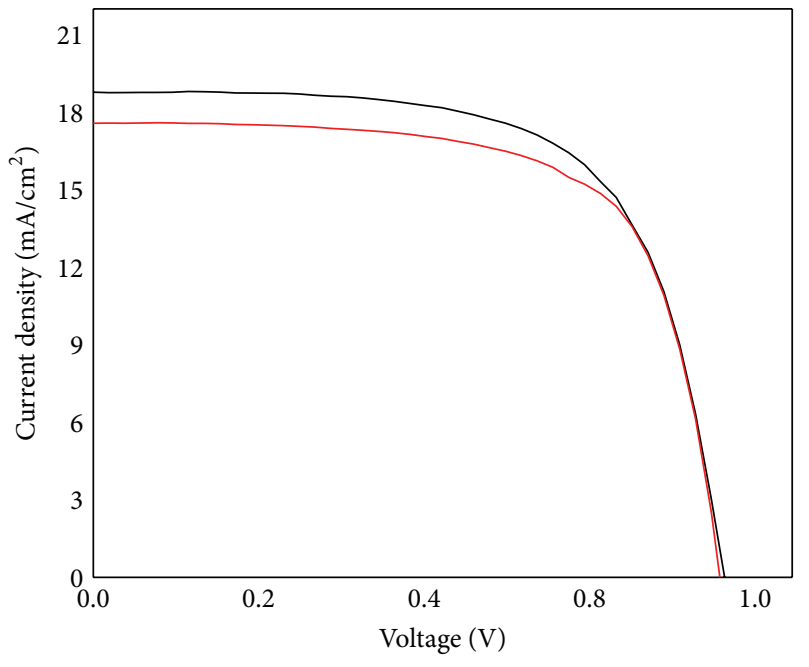

(a)

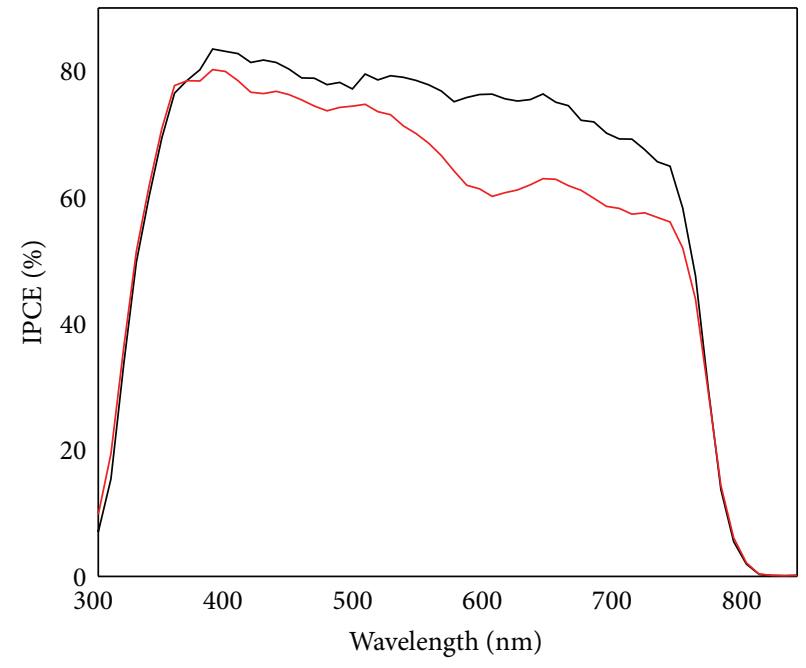

(b)

Figure 9: (a) $J-V$ curves and (b) IPCE spectra of vapor deposited (red line) versus spin-coated (black line) $\mathrm{PbI}_{2}$ layers in a perovskite cell. Reproduced from [23] with permission from the Royal Society of Chemistry.

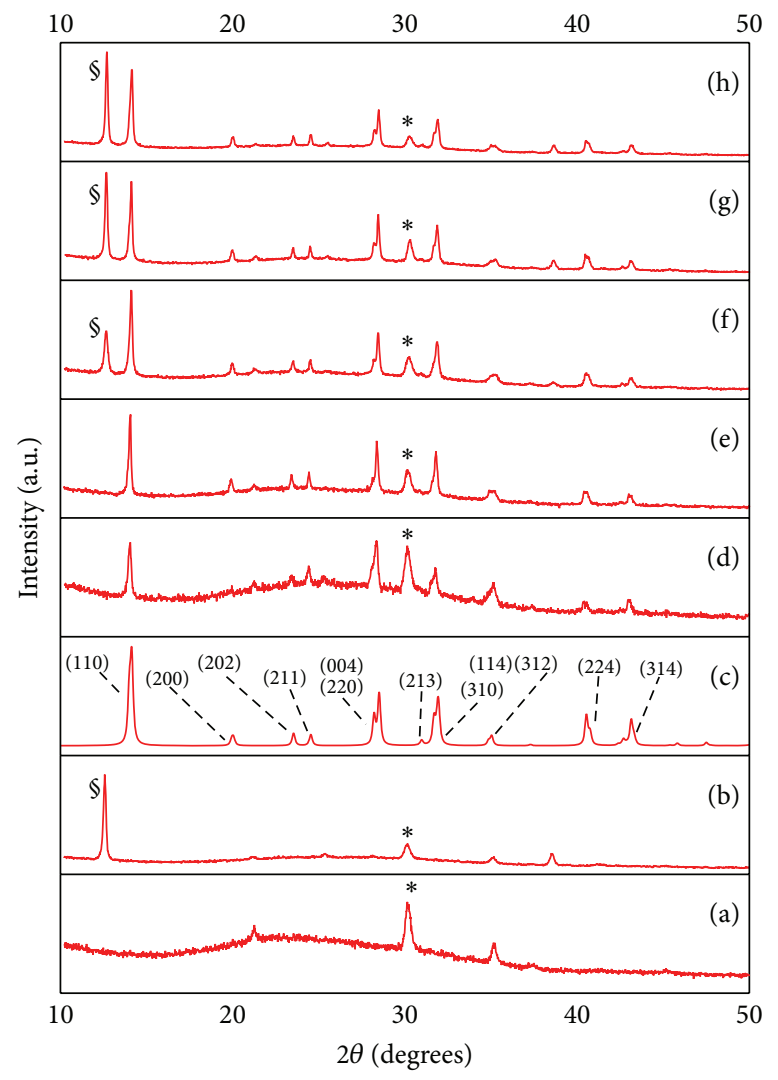

Figure 10: PXRD of (a) bare ITO/ZnO, (b) $\mathrm{PbI}_{2}$, (c) calculated tetragonal $\mathrm{CH}_{3} \mathrm{NH}_{3} \mathrm{PbI}_{3}$, (d) $61 \mathrm{~nm}$ thick $\mathrm{CH}_{3} \mathrm{NH}_{3} \mathrm{PbI}_{3}$, (e) $200 \mathrm{~nm}$ $\mathrm{CH}_{3} \mathrm{NH}_{3} \mathrm{PbI}_{3}$, (f) $280 \mathrm{~nm} \mathrm{CH} \mathrm{NH}_{3} \mathrm{PbI}_{3}$, (g) $400 \mathrm{~nm} \mathrm{CH} \mathrm{NH}_{3} \mathrm{PbI}_{3}$, and (h) $560 \mathrm{~nm} \mathrm{CH} \mathrm{NH}_{3} \mathrm{PbI}_{3}$. $\S$ refers to a peak that is indicative of crystalline $\mathrm{PbI}_{2}$ and $*$ is indicative of ITO glass substrate. As the perovskite layer thickness increases, the unreacted crystalline $\mathrm{PbI}_{2}$ also increases. Reproduced from [23] with permission from the Royal Society of Chemistry. 


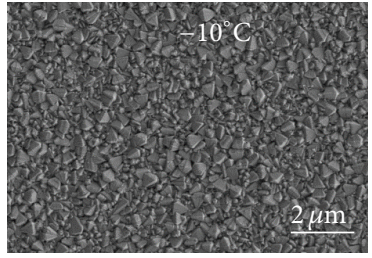

(a)

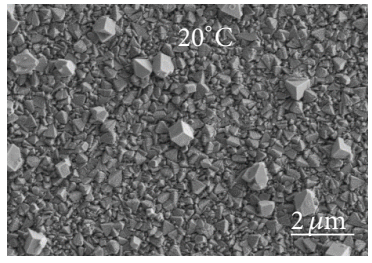

(c)

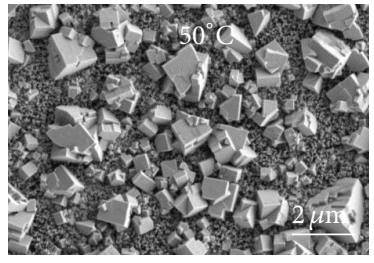

(e)

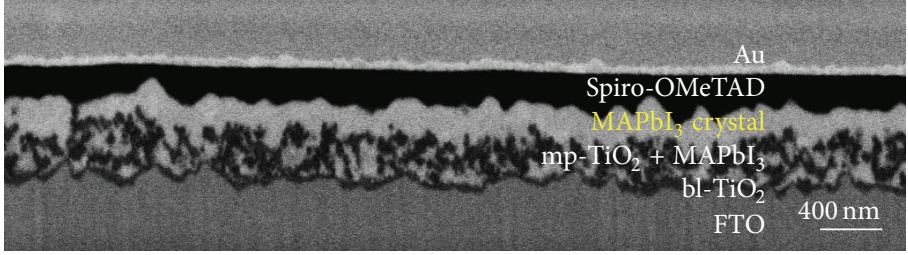

(b)

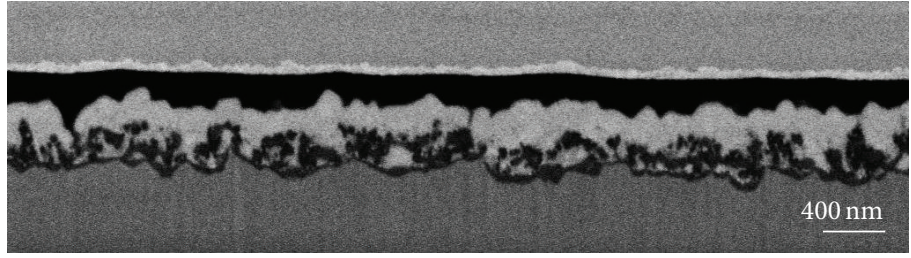

(d)

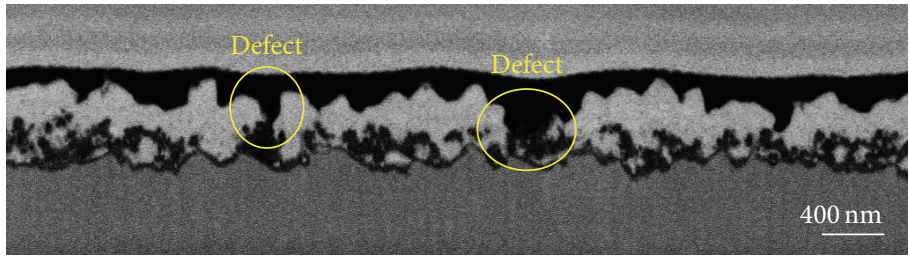

(f)

Figure 11: (a) Top-down SEM for $-10^{\circ} \mathrm{C}$. (b) Cross-sectional SEM for $-10^{\circ} \mathrm{C}$. (c) Top-down SEM for $20^{\circ} \mathrm{C}$. (d) Cross-sectional SEM for $20^{\circ} \mathrm{C}$. (e) Top-down SEM for $50^{\circ} \mathrm{C}$. (f) Cross-sectional SEM for $50^{\circ} \mathrm{C}$. Reproduced from [24] with permission from the Royal Society of Chemistry.

TABLE 4: Electrical data for $-10^{\circ} \mathrm{C}, 20^{\circ} \mathrm{C}$, and $50^{\circ} \mathrm{C}$. Reproduced from [24] with permission from the Royal Society of Chemistry.

\begin{tabular}{lcccc}
\hline $\begin{array}{l}\text { Reaction } \\
\text { temperature } \\
\left({ }^{\circ} \mathrm{C}\right)\end{array}$ & $J_{\mathrm{sc}}\left(\mathrm{mA} \mathrm{cm}^{-2}\right)$ & $V_{\mathrm{oc}}(\mathrm{V})$ & FF & PCE (\%) \\
\hline-10 & 19.33 & 1.010 & 0.70 & 13.67 \\
20 & 19.84 & 1.014 & 0.71 & 14.28 \\
50 & 20.29 & 0.956 & 0.69 & 13.38 \\
\hline
\end{tabular}

grain size changes with temperature, which is consistent with computational analysis. An important observation is seen within Figure 11(f) where defects in the crystal structure are observed leading to direct contact between the electron transport layer (ETL) and hole transport layer (HTL).

The effect of reaction temperature on photovoltaic performance is shown in Table 4, namely, on short-circuit current density $\left(J_{\mathrm{sc}}\right)$, open-circuit voltage $\left(V_{\mathrm{oc}}\right)$, fill factor $(\mathrm{FF})$, and power conversion efficiency (PCE). As seen in Table $4, J_{\text {sc }}$ increases as the reaction temperature increases, which may be related to the increase in light absorption seen with the UVvis in Figure 12. The perovskite layer color becomes darker with increasing grain size.

However, as temperature increased, $V_{\mathrm{oc}}$ and FF decreased. This is most likely caused by defects seen in the SEM images. The defects, which were caused by the increase of grain size with temperature, serve as recombination sites between the HTL and ETL. Both $V_{\text {oc }}$ and FF parameters are dependent on the thickness of the perovskite layer as well as the mesoporous
$\mathrm{TiO}_{2}$ layer. The absorbance data seen in Figure 12 shows that absorbance is highest when the MAI solution is at $20^{\circ} \mathrm{C}$ and lowest for $-10^{\circ} \mathrm{C}$. This decrease in absorbance arises from decreasing grain size. This suggests that the low absorbance observed for crystals grown at $-10^{\circ} \mathrm{C}$ results from crystals with small grain sizes.

To elucidate the relationship between grain size and temperature of MAI solution, Ahn and colleagues utilized a series of mathematical equations. They observed that as the temperature of the MAI solution increased, the equilibrium concentration of the chemical reaction and thereby the free energy increased. Indeed, the experimental observations were consistent with mathematical findings.

\section{Future Outlook and Conclusions}

Understanding the solution processing conditions of perovskite-based solar cells remains at a nascent stage. Nonetheless, there are important challenges that must be addressed in order to fully realize their applicability. Recognizing that the crystal growth depends on the temperature, one way of boosting grain size would be to improve solution deposition temperatures, annealing times, and annealing temperatures, for example, continuing to elucidate the relationship between solution temperatures of MAI and crystal growth, since this is an underexplored research area. Current work involves replacing MAI with formamidinium iodide (FAI) to improve the range of absorption [34]. No current study exists to show the effects of solution temperature of the FAI precursor on the crystal 


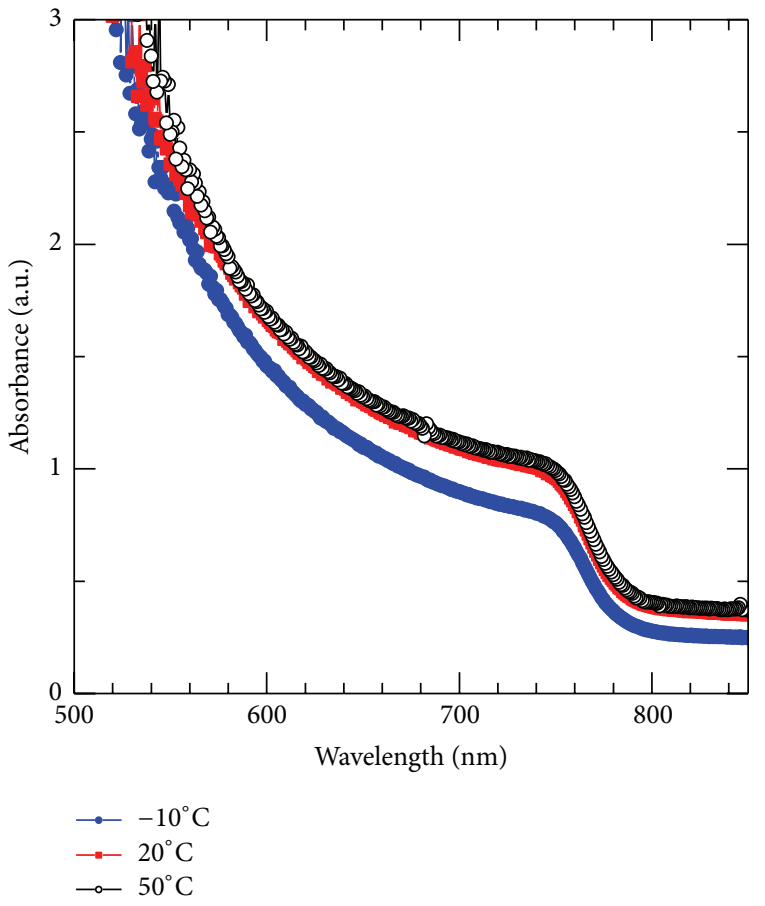

Figure 12: Absorbance spectra for $-10^{\circ} \mathrm{C}, 20^{\circ} \mathrm{C}$, and $50^{\circ} \mathrm{C}$. Reproduced from [24] with permission from the Royal Society of Chemistry.

grain size. The trade-offs between crystal growth, grain boundary size, film thickness, film absorption, and so on are sufficiently intertwined. Optimization of trade-offs might benefit greatly from computational and mathematical modeling. Indeed, this idea has proven valuable in the context of perovskite application challenges but has been inadequately explored $[11,24]$. The ties between the diversity of fabrication approaches and resulting film morphology and optoelectronic and performance properties must be simultaneously understood and optimized before we can move further in this field of research.

Over the past five years, the emergence of perovskite solar cells as energy conversion devices has advanced exponentially. This is due to the plethora of experimental and theoretical studies that have been contributed to the field. However, despite their popularity, there is much room for improvement. Recent studies have suggested the importance of understanding grain size and enhanced photovoltaic performance. We suspect that simultaneous optimization of processing conditions, resulting morphology, and performance of these thin films will be possible through a collaborative effort between synthetic, computational, and materials chemists. Only then can efficient, solution-processable perovskite-based solar cells advance forward as a commercializable technology.

\section{Competing Interests}

The authors declare that there are no competing interests regarding the publication of this paper.

\section{Authors' Contributions}

Jeremy L. Barnett, Vivien L. Cherrette, and Connor J. Hutcherson contributed equally to this work.

\section{Acknowledgments}

Monica C. So acknowledges financial support from the California State University, Chico.

\section{References}

[1] J. Burschka, N. Pellet, S.-J. Moon et al., "Sequential deposition as a route to high-performance perovskite-sensitized solar cells," Nature, vol. 499, no. 7458, pp. 316-319, 2013.

[2] H.-B. Kim, H. Choi, J. Jeong et al., "Mixed solvents for the optimization of morphology in solution-processed, invertedtype perovskite/fullerene hybrid solar cells," Nanoscale, vol. 6, no. 12, pp. 6679-6683, 2014.

[3] Y. Wu, A. Islam, X. Yang et al., "Retarding the crystallization of $\mathrm{PbI} 2$ for highly reproducible planar-structured perovskite solar cells via sequential deposition," Energy and Environmental Science, vol. 7, no. 9, pp. 2934-2938, 2014.

[4] N. J. Jeon, J. H. Noh, Y. C. Kim, W. S. Yang, S. Ryu, and S. I. Seok, "Solvent engineering for high-performance inorganic-organic hybrid perovskite solar cells," Nature Materials, vol. 13, no. 9, pp. 897-903, 2014.

[5] P. Gao, M. Grätzel, and M. K. Nazeeruddin, "Organohalide lead perovskites for photovoltaic applications," Energy and Environmental Science, vol. 7, no. 8, pp. 2448-2463, 2014.

[6] H. S. Jung and N.-G. Park, "Perovskite solar cells: from materials to devices," Small, vol. 11, no. 1, pp. 10-25, 2015.

[7] A. Sharenko and M. F. Toney, "Relationships between lead halide perovskite thin-film fabrication, morphology, and performance in solar cells," Journal of the American Chemical Society, vol. 138, no. 2, pp. 463-470, 2016.

[8] Y. Zhao and K. Zhu, "Solution chemistry engineering toward high-efficiency perovskite solar cells," Journal of Physical Chemistry Letters, vol. 5, no. 23, pp. 4175-4186, 2014.

[9] Y. Tidhar, E. Edri, H. Weissman et al., "Crystallization of methyl ammonium lead halide perovskites: implications for photovoltaic applications," Journal of the American Chemical Society, vol. 136, no. 38, pp. 13249-13256, 2014.

[10] A. Marchioro, J. Teuscher, D. Friedrich et al., "Unravelling the mechanism of photoinduced charge transfer processes in lead iodide perovskite solar cells," Nature Photonics, vol. 8, no. 3, pp. 250-255, 2014.

[11] J. Berry, T. Buonassisi, D. A. Egger et al., "Hybrid organicinorganic perovskites (HOIPs): opportunities and challenges," Advanced Materials, vol. 27, no. 35, pp. 5102-5112, 2015.

[12] G. E. Eperon, S. N. Habisreutinger, T. Leijtens et al., "The importance of moisture in hybrid lead halide perovskite thin film fabrication," ACS Nano, vol. 9, no. 9, pp. 9380-9393, 2015.

[13] Y. Ma, S. Wang, L. Zheng et al., "Recent research developments of perovskite solar cells," Chinese Journal of Chemistry, vol. 32, no. 10, pp. 957-963, 2014.

[14] J. S. Manser, M. I. Saidaminov, J. A. Christians, O. M. Bakr, and P. V. Kamat, "Making and breaking of lead halide perovskites," Accounts of Chemical Research, vol. 49, no. 2, pp. 330-338, 2016. 
[15] G. Niu, W. Li, F. Meng, L. Wang, H. Dong, and Y. Qiu, "Study on the stability of $\mathrm{CH}_{3} \mathrm{NH}_{3} \mathrm{PbI}_{3}$ films and the effect of postmodification by aluminum oxide in all-solid-state hybrid solar cells," Journal of Materials Chemistry A, vol. 2, no. 3, pp. 705-710, 2014.

[16] S. Pathak, A. Sepe, A. Sadhanala et al., "Atmospheric influence upon crystallization and electronic disorder and its impact on the photophysical properties of organic-inorganic perovskite solar cells," ACS Nano, vol. 9, no. 3, pp. 2311-2320, 2015.

[17] S. Wozny, M. Yang, A. M. Nardes et al., "Controlled humidity study on the formation of higher efficiency formamidinium lead triiodide-based solar cells," Chemistry of Materials, vol. 27, no. 13, pp. 4814-4820, 2015.

[18] D. Khatiwada, S. Venkatesan, N. Adhikari et al., "Efficient perovskite solar cells by temperature control in single and mixed halide precursor solutions and films," Journal of Physical Chemistry C, vol. 119, no. 46, pp. 25747-25753, 2015.

[19] D. Wang, Z. Liu, Z. Zhou et al., "Reproducible one-step fabrication of compact MAPbI3-xClx thin films derived from mixed-lead-halide precursors," Chemistry of Materials, vol. 26, no. 24, pp. 7145-7150, 2014.

[20] A. Dualeh, N. Tétreault, T. Moehl, P. Gao, M. K. Nazeeruddin, and M. Grätzel, "Effect of annealing temperature on film morphology of organic-inorganic hybrid pervoskite solid-state solar cells," Advanced Functional Materials, vol. 24, no. 21, pp. 3250-3258, 2014.

[21] C. Bi, Y. Shao, Y. Yuan et al., "Understanding the formation and evolution of interdiffusion grown organolead halide perovskite thin films by thermal annealing," Journal of Materials Chemistry A, vol. 2, no. 43, pp. 18508-18514, 2014.

[22] T. Ma, M. Cagnoni, D. Tadaki, A. Hirano-Iwata, and M. Niwano, "Annealing-induced chemical and structural changes in tri-iodide and mixed-halide organometal perovskite layers," Journal of Materials Chemistry A, vol. 3, no. 27, pp. 14195-14201, 2015.

[23] D. Liu, M. K. Gangishetty, and T. L. Kelly, "Effect of $\mathrm{CH}_{3} \mathrm{NH}_{3} \mathrm{PbI}_{3}$ thickness on device efficiency in planar heterojunction perovskite solar cells," Journal of Materials Chemistry A, vol. 2, no. 46, pp. 19873-19881, 2014.

[24] N. Ahn, S. M. Kang, J.-W. Lee, M. Choi, and N.-G. Park, "Thermodynamic regulation of $\mathrm{CH} 3 \mathrm{NH} 3 \mathrm{PbI} 3$ crystal growth and its effect on photovoltaic performance of perovskite solar cells," Journal of Materials Chemistry A, vol. 3, pp. 19901-19906, 2015.

[25] M. Saliba, K. W. Tan, H. Sai et al., "Influence of thermal processing protocol upon the crystallization and photovoltaic performance of organic-inorganic lead trihalide perovskites," Journal of Physical Chemistry C, vol. 118, no. 30, pp. 17171-17177, 2014.

[26] B. Jeong, S. M. Cho, S. H. Cho et al., "Humidity controlled crystallization of thin $\mathrm{CH}_{3} \mathrm{NH}_{3} \mathrm{PbI}_{3}$ films for high performance perovskite solar cell," Physica Status Solidi (RRL)—Rapid Research Letters, vol. 10, no. 5, pp. 381-387, 2016.

[27] P. Qin, S. Tanaka, S. Ito et al., "Inorganic hole conductorbased lead halide perovskite solar cells with $12.4 \%$ conversion efficiency," Nature Communications, vol. 5, article 3834, 2014.

[28] V. O. Eze, B. Lei, and T. Mori, "Air-assisted flow and two-step spin-coating for highly efficient $\mathrm{CH}_{3} \mathrm{NH}_{3} \mathrm{PbI}_{3}$ perovskite solar cells," Japanese Journal of Applied Physics, vol. 55, Article ID 02BF08, 2016.

[29] J. Shi, Y. Luo, H. Wei et al., "Modified two-step deposition method for high-efficiency $\mathrm{TiO}_{2} / \mathrm{CH}_{3} \mathrm{NH}_{3} \mathrm{PbI}_{3}$ heterojunction solar cells," ACS Applied Materials and Interfaces, vol. 6, no. 12, pp. 9711-9718, 2014.

[30] L. Zheng, Y. Ma, S. Chu et al., "Improved light absorption and charge transport for perovskite solar cells with rough interfaces by sequential deposition," Nanoscale, vol. 6, no. 14, pp. 81718176, 2014.

[31] R. Sheng, A. Ho-Baillie, S. Huang et al., "Methylammonium lead bromide perovskite-based solar cells by vapor-assisted deposition," Journal of Physical Chemistry C, vol. 119, no. 7, pp. 3545-3549, 2015.

[32] P. Cui, P. Fu, D. Wei et al., "Reduced surface defects of organometallic perovskite by thermal annealing for highly efficient perovskite solar cells," RSC Advances, vol. 5, no. 92, pp. 75622-75629, 2015.

[33] D. Bi, A. M. El-Zohry, A. Hagfeldt, and G. Boschloo, "Improved morphology control using a modified two-step method for efficient perovskite solar cells," ACS Applied Materials and Interfaces, vol. 6, no. 21, pp. 18751-18757, 2014.

[34] N. Pellet, P. Gao, G. Gregori et al., "Mixed-organic-cation perovskite photovoltaics for enhanced solar-light harvesting," Angewandte Chemie - International Edition, vol. 53, no. 12, pp. 3151-3157, 2014.

[35] E. L. Unger, A. R. Bowring, C. J. Tassone et al., "Chloride in lead chloride-derived organo-metal halides for perovskite-absorber solar cells," Chemistry of Materials, vol. 26, no. 24, pp. 7158-7165, 2014.

[36] H. Zhou, Q. Chen, G. Li et al., "Interface engineering of highly efficient perovskite solar cells," Science, vol. 345, no. 6196, pp. 542-546, 2014.

[37] C. W. Chen, H. W. Kang, S. Y. Hsiao, P. F. Yang, K. M. Chiang, and H. W. Lin, "Efficient and uniform planar-type perovskite solar cells by simple sequential vacuum deposition," Advanced Materials, vol. 26, no. 38, pp. 6647-6652, 2014.

[38] K. Liang, D. B. Mitzi, and M. T. Prikas, "Synthesis and characterization of organic-inorganic perovskite thin films prepared using a versatile two-step dipping technique," Chemistry of Materials, vol. 10, no. 1, pp. 403-411, 1998.

[39] J. Jiang, H. Jun Tao, S. Chen et al., "Efficiency enhancement of perovskite solar cells by fabricating as-prepared film before sequential spin-coating procedure," Applied Surface Science, vol. 371, pp. 289-295, 2016.

[40] A. Yella, L.-P. Heiniger, P. Gao, M. K. Nazeeruddin, and M. Grätzel, "Nanocrystalline rutile electron extraction layer enables low-temperature solution processed perovskite photovoltaics with $13.7 \%$ efficiency," Nano Letters, vol. 14, no. 5, pp. 2591-2596, 2014.

[41] H.-S. Kim and N.-G. Park, "Parameters affecting $I-V$ hysteresis of $\mathrm{CH}_{3} \mathrm{NH}_{3} \mathrm{PbI}_{3}$ perovskite solar cells: effects of perovskite crystal size and mesoporous $\mathrm{TiO}_{2}$ layer," Journal of Physical Chemistry Letters, vol. 5, no. 17, pp. 2927-2934, 2014. 

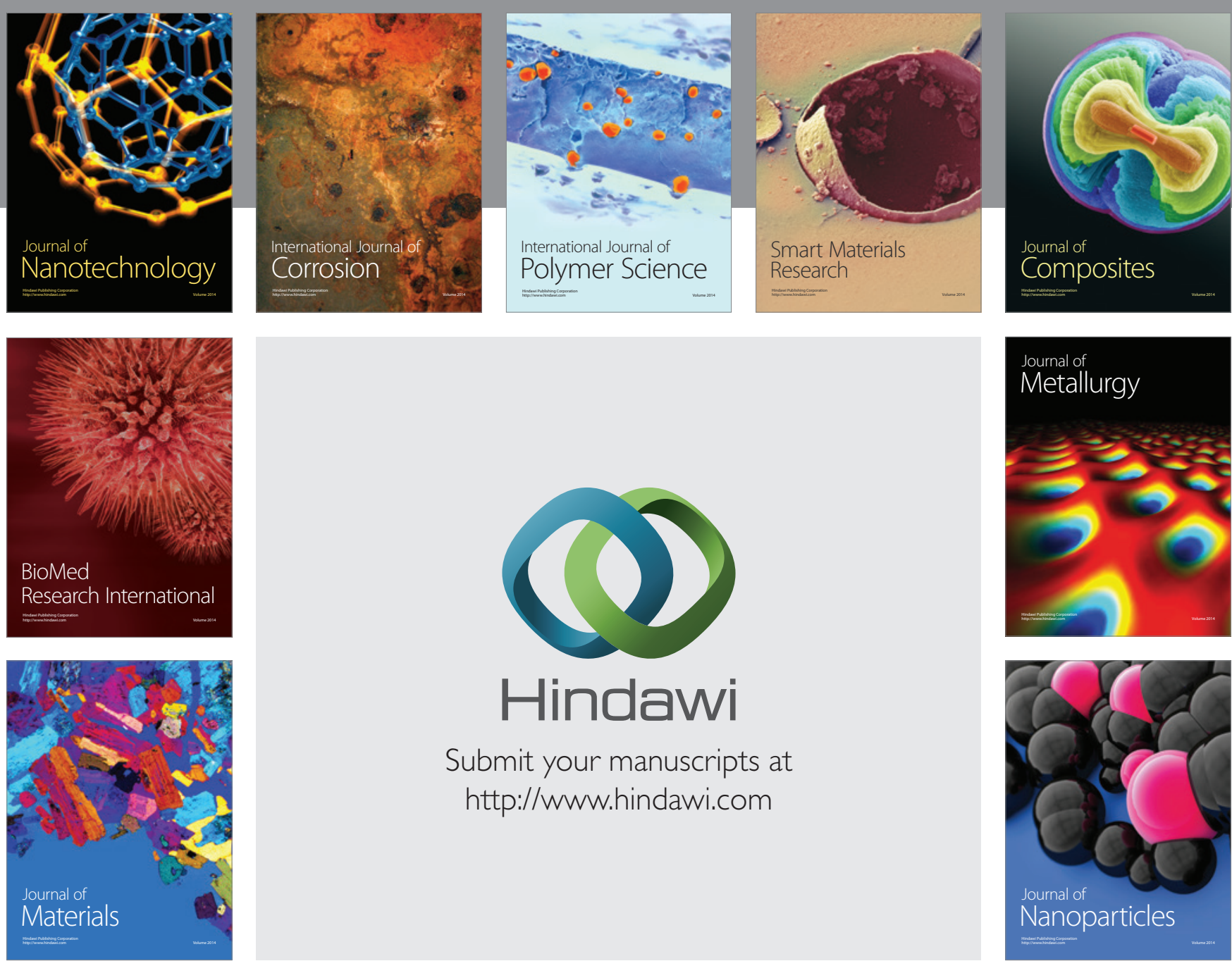

\section{Hindawi}

Submit your manuscripts at

http://www.hindawi.com

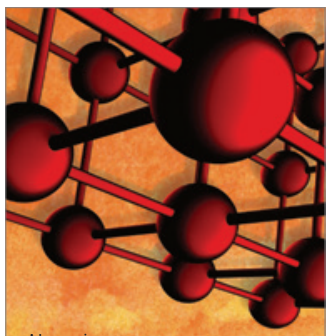

Materials Science and Engineering
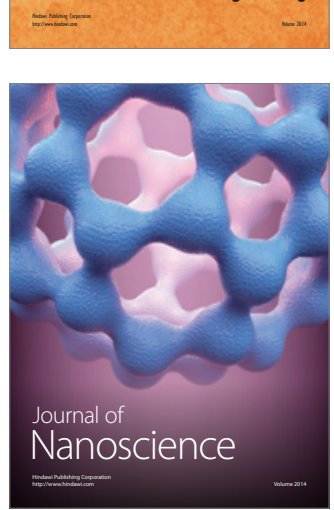
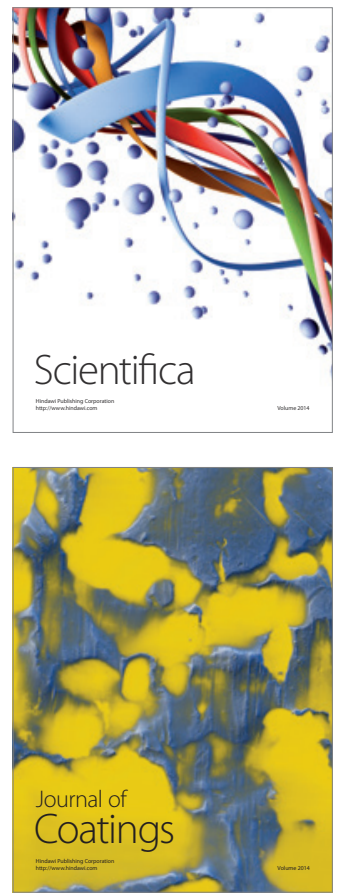
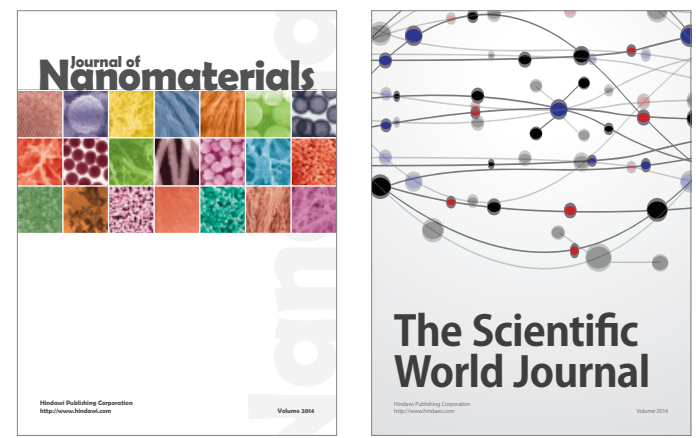

The Scientific World Journal
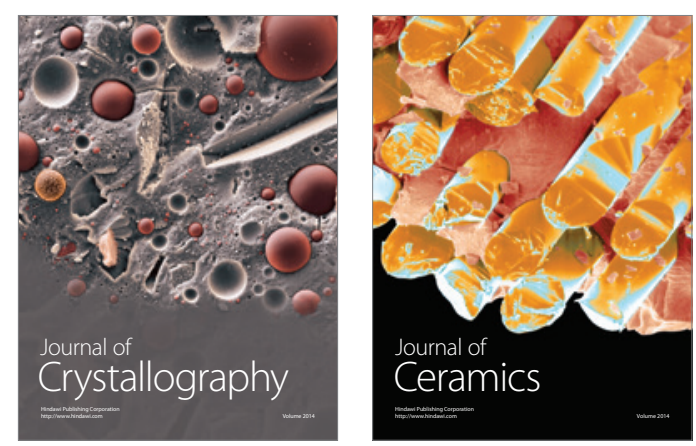
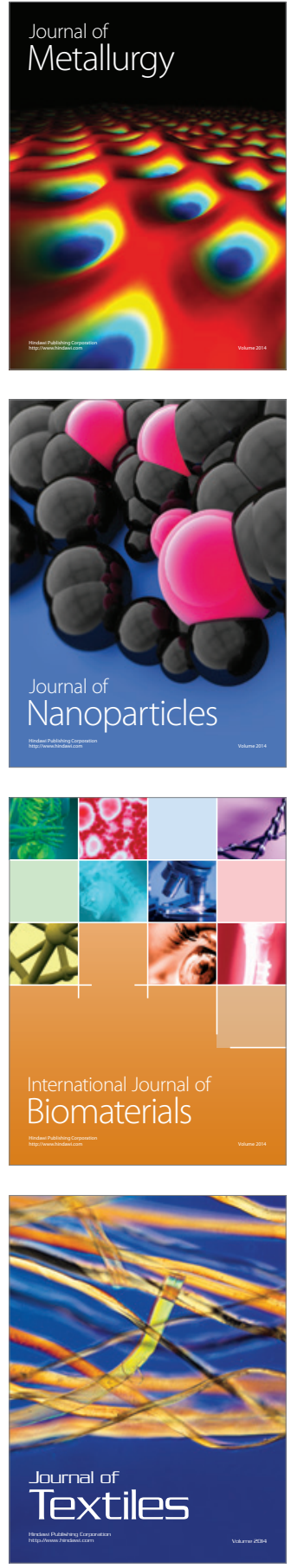